\title{
Use of long-term antibiotic treatment in COPD patients in the UK: a retrospective cohort study
}

\section{Gareth Dean Russell James ${ }^{1,2}$, Irene Petersen1, Irwin Nazareth1, Jadwiga A Wedzicha², * Gavin C Donaldson²}

\author{
Department of Primary Care and Population Health, UCL Medical School, Royal Free Campus, London, UK \\ ${ }^{2}$ Centre for Respiratory Medicine, University College London, Royal Free Campus, London, UK
}

Originally received 9th October 2012; resubmitted 11th January 2013; revised 16th January 2013; further revision 3rd April 2013; accepted 12th April 2013; online 9th July 2013

\begin{abstract}
Background: Exacerbations of chronic obstructive pulmonary disease (COPD) are a burden to patients and impose a major cost on health services. Long-term antibiotic therapy may prevent exacerbations, but at present it is not recommended by management guidelines.

Aims: To identify the type and prevalence of long-term oral antibiotic treatments prescribed to patients with COPD and to assess the patient characteristics associated with long-term antibiotic use.

Methods: A retrospective cohort using all eligible practices in The Health Improvement Network (THIN) UK primary care database between 2000 and 2009 was studied. We identified patients with COPD and then those who received a course of long-term antibiotics. Long-term courses were defined as $\geq 6$ months in duration with $<50 \%$ concomitant oral corticosteroid treatment.

Results: We identified 92,576 patients with COPD, but only 567 patients (0.61\%) who received 998 long-term antibiotic courses. Mean follow-up time was 3 years and 10 months. The median long-term antibiotic course length was 280 days (interquartile range 224, 394) and 58 patients $(0.06 \%)$ were continuously prescribed antibiotics for $>2$ years. The most commonly used long-term antibiotics were oxytetracycline, doxycycline, and penicillin. Azithromycin, erythromycin, and clarithromycin were less frequently used. There was little evidence of the use of rotating courses of antibiotics. Men, people aged 50-79 years, non-smokers, and patients with poorer lung function were more likely to receive long-term antibiotic treatment.

Conclusions: Relatively few COPD patients are currently prescribed long-term antibiotics. Further clinical trials are required to determine the efficacy of this therapy. If beneficial, the use of such treatments should be incorporated into clinical guidelines.

C 2013 Primary Care Respiratory Society UK. All rights reserved.

GDR James et al. Prim Care Respir J 2013; 22(3): 271-277

http://dx.doi.org/10.4104/pcrj.2013.00061
\end{abstract}

Keywords COPD, antibiotics, long-term, cohort

See linked editorial by Miravitlles on pg 261

The full version of this paper, with online appendix,

is available online at www.thepcrj.org

\section{Introduction}

Chronic obstructive pulmonary disease (COPD) is a major worldwide cause of mortality.1.2 There are an estimated 900,000 diagnosed sufferers in the UK alone, ${ }^{3}$ and the disease costs the UK National Health Service (NHS) over $\mathrm{f} 253$ million a year. ${ }^{4}$

Many patients experience exacerbations during the course of COPD. ${ }^{5}$ These are episodes of acute worsening of respiratory systems that reduce the quality of life, ${ }^{6}$ hasten lung function decline, ${ }^{7}$ and may cause death. ${ }^{5} \mathrm{~A}$ third of patients with moderate to severe COPD suffer two or more exacerbations per year. ${ }^{8}$ The treatment of exacerbations constitutes $60 \%$ of the total cost of COPD to the $\mathrm{NHS}^{9}$ and generally involves a short course of antibiotics and/or oral corticosteroids, but in more severe cases may require hospitalisation. ${ }^{3}$

Current pharmacological and physiological therapies for preventing exacerbations involve daily treatment with long-acting bronchodilators and/or inhaled corticosteroids together with pulmonary rehabilitation, smoking cessation, and influenza immunisation. ${ }^{10}$ Although these therapies can reduce exacerbation

\footnotetext{
* Corresponding author: Dr Gavin C Donaldson, Centre for Respiratory Medicine, University College London, Royal Free Campus, Rowland Hill Street, Hampstead, London NW3 2PF, UK. Tel: +44 (0)20 7794 0500, ext 34308. E-mail: g.donaldson@ucl.ac.uk
} 
rates, additional approaches are needed.

One possibility is long-term antibiotic treatment, but there is patchy evidence of any benefit. The clinical trials reported in the 1970s indicated only a marginal benefit in reducing exacerbation frequency and there have been no recent studies with these older antibiotics. A clinical trial of pulsed moxifloxacin did not show a significant reduction in exacerbation frequency in the intention-totreat population." A post hoc analysis did show a significant reduction in exacerbation frequency in patients with mucopurulent/purulent sputum production. The greatest successes have been achieved with macrolides. In a recent large study of 1,142 COPD patients randomly assigned to daily $250 \mathrm{mg}$ azithromycin or placebo, exacerbation frequency fell significantly from 1.83 per patient-year on placebo to 1.48 per patient-year with azithromycin. ${ }^{12}$ The rate ratio (from negative binomial regression) was 0.83 . In a smaller placebo-controlled randomised clinical trial of erythromycin administered in a dose of $250 \mathrm{mg}$ twice daily there was a significant reduction from a median of two exacerbations per year with placebo to one exacerbation per year with erythromycin. The rate ratio from generalised linear modelling was $0.65 .{ }^{13}$

Currently, long-term antibiotic treatment is not recommended by the National Institute for Health and Clinical Excellence (NICE) and Global Initiative for Chronic Obstructive Lung Disease (GOLD) ${ }^{14}$ COPD management guidelines because of clinical uncertainty and concerns about safety relative to benefit, particularly the development of resistant bacteria. Despite the guidelines, long-term antibiotic therapy is currently prescribed as these patients are occasionally seen in clinic, but its prevalence and characteristics are unknown and such information is therefore useful.

Using data from The Health Improvement Network (THIN) primary care database, this study aims to identify the number and type of antibiotics prescribed long-term to patients with COPD by general practitioners (GP) and the length of treatment, and to assess the patient characteristics associated with long-term antibiotic use.

\section{Methods}

\section{Data source}

In the UK, approximately $98 \%$ of patients are registered with a GP15 and COPD is primarily managed in general practice. Medical symptoms and diagnosis, health indicators such as weight and blood pressure, and prescribed medicines are recorded during consultations with the GP. THIN contains anonymised records of $6 \%$ of the UK population (http://www.epic-uk.org/our-data/statistics. shtml) and has been validated for pharmacoepidemiological research. ${ }^{16}$ THIN is broadly representative of UK general practice in terms of age, gender, and smoking status. ${ }^{17,18}$ Prescription data are comparable with national statistics ${ }^{19}$ and $>98 \%$ of prescriptions are redeemed. ${ }^{20}$ In the UK, GPs are not required to record the indication for prescriptions and do so less than $65 \%$ of the time. ${ }^{21,22}$ Recorded diagnoses and symptoms are classified using Read codes. ${ }^{23}$ The dataset also includes Townsend quintile, a measure of social deprivation where 5 indicates most deprived and 1 indicates least deprived. ${ }^{24}$ The prevalence, demographics, smoking habits, and mortality of patients with COPD in THIN is similar to national data. ${ }^{25}$

The THIN scheme for obtaining and providing anonymous patient data to researchers was approved by the National Health Service South-East Multicenter Research Ethics Committee (MREC) in 2002. This particular study was also reviewed by THIN Scientific Review Committee.

\section{Study population}

We identified patients aged 35-89 years between 1 January 2000 and 31 December 2009 with a diagnosis of COPD. The diagnosis was based on the Quality and Outcomes Framework (QOF) codes for COPD. These have been shown to select a subset of patients whose prevalence, geographical distribution, age, and gender distribution matches other national surveys of $\mathrm{COPD}^{25}$ and has been used in other COPD studies. ${ }^{26}$ People were eligible for entry to the study from the latest of either 1 January 2000, the patient joining the practice, their 35th birthday or diagnosis with COPD, or the date the practice started to contribute data to THIN. Data on eligible patients were collected until the earliest date of either death, transfer to another practice or 31 December 2009. Practices in THIN were excluded until they met acceptable recording standards - that is, records are of good quality and mortality rates are comparable to the expected UK national age- and gender-specific mortality rates ${ }^{27}$ to ensure accurate data recording.

Information on gender, age, last recorded smoking status (active/non-smoker), forced expiratory volume in one second ( $\left.\mathrm{FEV}_{1}\right)$, forced vital capacity ( $F V C$ ), $\mathrm{FEV}_{1} / \mathrm{FV}$ ratio, and Townsend quintile value were extracted from the database. Predicted $\mathrm{FEV}_{1}$ was estimated using age, sex and height. FEV 1 and FVC measurements between $0.3 \mathrm{~L}$ and $7.0 \mathrm{~L}$ were considered as valid measures.

\section{Antibiotics}

Patients can be treated with a very wide variety of antibiotics, so we limited our analysis to 10 oral antibiotics. Their choice was based on evidence from clinical trials that evaluated long-term use of azithromycin, erythromycin, moxifloxacin, clarithromycin, oxytetracycline, penicillin, and doxycycline (a tetracycline equivalent). Furthermore, we identified the antibiotics prescribed to COPD patients in THIN and included the three remaining most commonly used (amoxicillin, co-amoxiclav, and ciprofloxacin). Finally, we examined courses where these antibiotics have been prescribed in rotation but limited their combinations to just two different antibiotics within one long-term course.

The recent clinical trials of long-term antibiotics for prophylactic reduction of exacerbations have involved treatment for 12 months, ${ }^{11-13,28}$ but some of the older trials were for shorter periods..$^{29}$ We therefore focused on antibiotic courses lasting $\geq 6$ months (longterm) to avoid misidentification of repeated antibiotic courses in patients with frequent exacerbations.

\section{Prescription data}

For each patient we extracted information on all their oral antibiotic prescriptions together with medical diagnosis records on the day of prescription. Prescription length was calculated by dividing the prescription quantity by the number of tablets to be taken per day (dosage). Hot deck imputation with adjustment for prescription quantity was used to replace missing data with an estimate based 
on the typical dosage prescribed for each antibiotic. ${ }^{30}$ Long-term courses of antibiotics may consist of a number of consecutive prescriptions, but there may be gaps between prescriptions if the patient misses or postpones an appointment or delays picking up the next prescription. We took 10 days as the maximum period between the end of a course and the start of another for the two courses to be considered continuous. The course length was calculated from the start of the first prescription to the end of the last.

COPD patients can experience acute exacerbations that may occur in clusters, and receive repeated courses of antibiotics and/or oral corticosteroids. ${ }^{26,31}$ To minimise misclassification, we excluded long-term antibiotic courses where $\geq 50 \%$ of the individual antibiotic prescriptions were accompanied by a concurrent oral corticosteroid prescription. Sensitivity analysis showed that the relative distribution of antibiotic types used for long-term courses was the same irrespective of whether courses were concurrent with $0 \%$, $<50 \%$, or $\leq 100 \%$ oral corticosteroid prescriptions (data not shown).

\section{Statistical analysis}

Patient characteristics were described using means and percentages. The long-term courses with each type of antibiotic were described by their frequency and the number of unique patients who received them, their duration, and median with interquartile range (IQR), and by their dose in mg/day.

Long-term courses were broken down by those starting in the first five and final five years of the study. The number of long-term courses per 1,000 patient-years and the percentage of time patients spent on long-term therapy were also calculated.

We used logistic regression to assess the factors associated with long-term antibiotic use after initially adjusting for age and sex, and once again after adjusting for age, sex, smoking status, and Townsend quintile. The effect of COPD severity on receiving longterm antibiotic therapy was then separately evaluated by performing logistic regression on those with a $\mathrm{FEV}_{1} / \mathrm{FVC}$ record with adjustments made for age, sex, smoking status, and Townsend quintile. Data were 100\% complete for age and sex, 95\% Townsend quintile, $91 \%$ smoking status, $72 \% \mathrm{FEV}_{1}, 52 \% \mathrm{FVC}, 65 \% \mathrm{FEV} / \mathrm{FVC}$. All statistical analyses were conducted using Stata Version 12.0 (Stata Corporation, Texas, USA).

\section{Results}

\section{Patient characteristics}

A total of 2,839,694 patients aged 35-89 years were registered in 419 eligible practices in THIN between 2000 and 2009. Of these $92,576(3 \%)$ had a clinical record of COPD. The average time which COPD patients were registered with a general practice since diagnosis of COPD was 3 years and 10 months. The COPD patients were predominantly middle-aged or elderly, with $>96 \%$ aged $>50$ years, a third still smoked, and their mean $\mathrm{FEV}_{1}, \mathrm{FEV} 1 / \mathrm{FVC}$ ratio and $\mathrm{FEV}_{1} / \mathrm{FEV}_{1}$ predicted suggested that they had COPD (Table 1).

The COPD patients received 749,412 separate antibiotic prescriptions. The 10 most commonly prescribed antibiotics constituted $76 \%$ of the total prescriptions in the COPD patients; dosage information was unavailable for $15 \%$ of prescriptions.

A total of 998 long-term courses ( $\geq 6$ months) were prescribed to
Table 1. Characteristics of patients with a clinical record for COPD

\begin{tabular}{|c|c|c|c|}
\hline & Category & Frequency & $\%$ \\
\hline Total number of patients & - & 92,576 & - \\
\hline \multirow[t]{3}{*}{ Age (years) } & $35-49$ & 4,116 & 4 \\
\hline & $50-79$ & 68,447 & 74 \\
\hline & $80-89$ & 20,013 & 22 \\
\hline \multirow[t]{2}{*}{ Gender } & Male & 49,839 & 54 \\
\hline & Female & 42,737 & 46 \\
\hline \multirow[t]{6}{*}{ Townsend quintile } & 1 (least deprived) & 14,424 & 16 \\
\hline & 2 & 15,844 & 17 \\
\hline & 3 & 18,701 & 20 \\
\hline & 4 & 20,861 & 23 \\
\hline & 5 (most deprived) & 17,774 & 19 \\
\hline & Unknown & 4,972 & 5 \\
\hline \multirow[t]{5}{*}{ Smoking } & Non & 12,072 & 13 \\
\hline & Active & 27,336 & 30 \\
\hline & Ex & 44,380 & 48 \\
\hline & Unknown & 8,788 & 9 \\
\hline & & & Mean \\
\hline $\mathrm{FEV}_{1}$ (litres) & - & - & 1.4 \\
\hline FVC (litres) & - & - & 2.4 \\
\hline $\mathrm{FEV}_{1} / \mathrm{FVC}$ & - & - & 0.56 \\
\hline $\mathrm{FEV}_{1} / \mathrm{FEV}_{1}$ predicted & - & - & 0.59 \\
\hline
\end{tabular}

$\mathrm{COPD}=$ chronic obstructive pulmonary disease, $\mathrm{FEV}_{1}=$ forced expiratory volume in one second, FVC=forced vital capacity.

567 patients $(0.61 \%)$ and were used in the analysis. They received an average of two long-term courses (Table 2). This corresponds to three courses per 1,000 patient-years for all patients with COPD. The median course length was 280 days (IQR 224, 394). In the 233 patients who had two or more consecutive antibiotic courses there was no difference in the median length of the first courses (280 days, IQR 224, 394) compared with the consecutive courses. Courses consisted of a median of eight prescriptions (IQR 5, 12). The median length of each prescription was 28 days (IQR 28, 50). For those on a long-term course, $31 \%$ of their time in the practice (1 year and 2 months) was spent on long-term antibiotic therapy. Of the 998 courses, $811(81 \%)$ had no concurrent oral corticosteroid prescriptions. The remainder $(187,19 \%)$ received oral corticosteroids concurrently for a mean of $20 \%$ of antibiotic prescriptions within a long-term course. The 998 long-term courses consisted of 10,554 prescriptions in total, of which 1,347 (13\%) had their dose value imputed because it was not available. Had we not used hot deck imputation in these circumstances, it would have resulted in a reduction in the number of estimated long-term courses by 185 .

The three most commonly used long-term antibiotics were oxytetracycline, doxycycline, and penicillin (Table 3). Only two rotating courses (in one patient) and four courses of daily moxifloxacin were identified. Since 2005 , patients were significantly more likely to begin a long-term course of azithromycin $(p<0.01$, 
Table 2. Long-term ( $\geq 6$ months) antibiotic courses in COPD patients

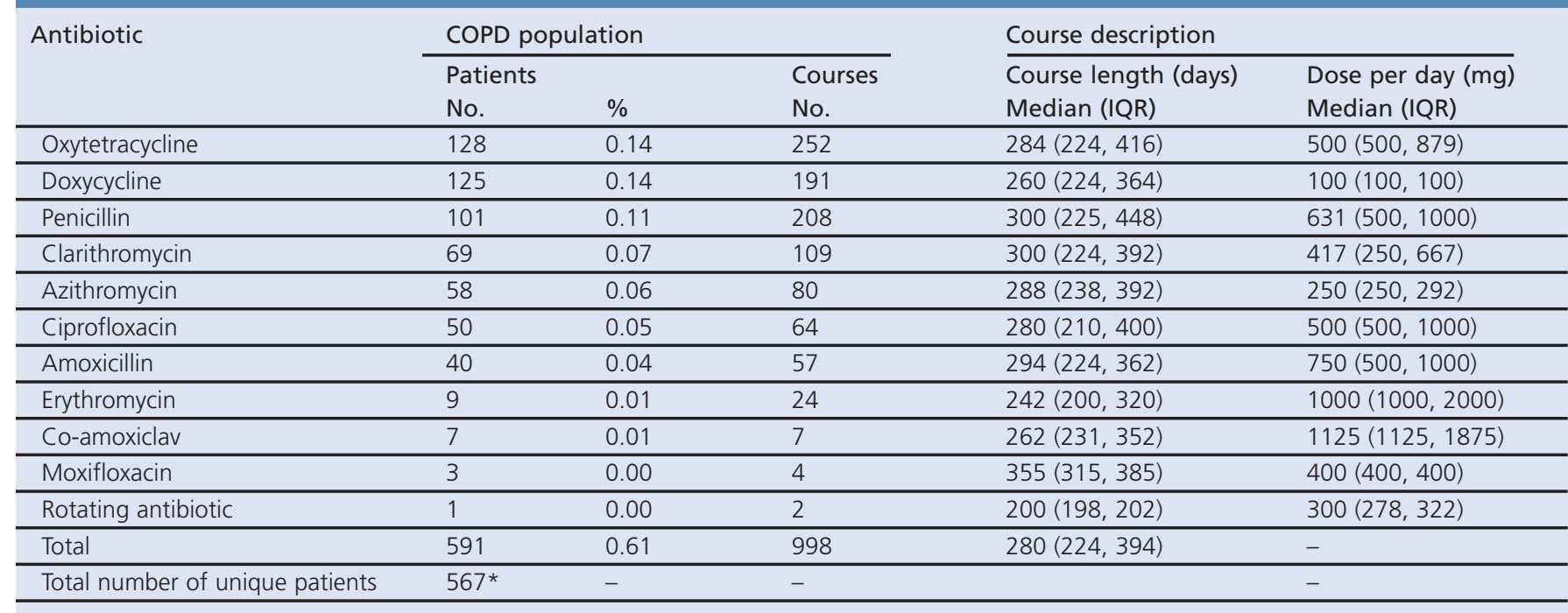

$\mathrm{COPD}=$ chronic obstructive pulmonary disease, IQR = interquartile range. *Number of unique patients (some patients had more than one type of antibiotic course).

Table 3. Long-term antibiotic course start dates

\begin{tabular}{|c|c|c|c|c|c|c|}
\hline \multirow[t]{2}{*}{ Antibiotic } & \multicolumn{2}{|c|}{ Start before $1 / 1 / 2005$} & \multicolumn{2}{|c|}{ Start on or after $1 / 1 / 2005$} & \multirow{2}{*}{$\frac{\text { Difference }}{\text { Post } 2005 \text { vs. pre } 2005}$} & \multirow[t]{2}{*}{$\mathrm{p}$ Value } \\
\hline & No. of courses & $\%$ & No. of courses & $\%$ & & \\
\hline Oxytetracycline & 103 & 30 & 149 & 23 & $7(-14,-1)$ & 0.03 \\
\hline Penicillin & 90 & 26 & 118 & 18 & $-8(-15,-2)$ & $<0.01$ \\
\hline Clarithromycin & 23 & 7 & 86 & 13 & $6(2,10)$ & $<0.01$ \\
\hline Azithromycin & 7 & 2 & 73 & 11 & $9(6,12)$ & $<0.01$ \\
\hline Amoxicillin & 20 & 6 & 37 & 6 & $0(-3,3)$ & 0.89 \\
\hline Erythromycin & 13 & 4 & 11 & 2 & $-1(-3,1)$ & 0.25 \\
\hline Co-amoxiclav & 3 & 1 & 4 & 1 & - & - \\
\hline Moxifloxacin & 0 & $<1$ & 4 & 1 & - & - \\
\hline Rotating antibiotic & 0 & $<1$ & 2 & $<1$ & - & - \\
\hline
\end{tabular}

Table 3) or clarithromycin $(p<0.01)$ and significantly less likely to begin a long-term course of penicillin $(p<0.01)$ or oxytetracycline $(p=0.03)$. Patients were equally likely to begin a long-term course of erythromycin $(p=0.25)$, doxycycline $(p=0.33)$, ciprofloxacin $(p=0.58)$, or amoxicillin $(p=0.89)$. There were insufficient data to assess changes in co-amoxiclav, moxifloxacin, or rotated antibiotics.

Of the 998 antibiotic courses, 489 had no associated diagnostic code entered in their record on prescription days within the duration of the course, 142 had codes referring to COPD, and 304 referred to conditions or indications for which antibiotic treatment would not be warranted (e.g. hypertension, headaches, sciatica). The remaining 63 courses had indications such as bronchiectasis (11 courses), dressing of wound, rosacea, acne vulgaris, folliculitis, splenectomy, aspergillosis, or Mycobacterium infection for which long-term antibiotics might be prescribed. If we excluded these 63 courses, the number of patients on a long-term course would fall from 567 $(0.61 \%)$ to $535(0.58 \%)$.
Being male, not smoking, or aged $50-79$ years was associated with a greater chance of being prescribed long-term antibiotics (Table 4). An obstructive ratio was not available for all patients but, of those with a $\mathrm{FEV}_{1} / \mathrm{FVC}$ record, $0.66 \%$ received a long-term course compared with $0.54 \%$ of patients without a $\mathrm{FEV}_{1} / \mathrm{FVC}$ record. The effects of the sociodemographic variables on the probability of receiving a long-term course did not change when the logistic model was rerun only including those with a $\mathrm{FEV}_{1} / \mathrm{FVC}$ record. However, in this sub-population, greater airways obstruction was associated with an increased likelihood of receiving a long-term course, a decrease of 1 unit in $\mathrm{FEV}_{1} / \mathrm{FVC}$ being associated with a $1 \%(95 \% \mathrm{Cl} 1 \%$ to $2 \%$ ) chance of a patient being prescribed long-term antibiotics.

\section{Discussion}

\section{Main findings}

The main findings of this study are that $0.61 \%$ of COPD patients have received a course of oral antibiotics lasting a median of 280 
Table 4. Odds of COPD patients taking long-term (LT) antibiotics for different subgroups

\begin{tabular}{|c|c|c|c|c|c|c|c|}
\hline \multirow[b]{2}{*}{ Variable } & \multirow[b]{2}{*}{ Category } & \multirow[b]{2}{*}{ No LT } & \multirow[b]{2}{*}{ LT } & \multicolumn{2}{|c|}{ Adjusted for age and sex } & \multicolumn{2}{|c|}{$\begin{array}{l}\text { Adjusted for age, sex, } \\
\text { smoking, and TQ }\end{array}$} \\
\hline & & & & Odds ratio & $p$ Value & Odds ratio & p Value \\
\hline Total number of patients $(n)$ & - & 92,009 & 567 & - & - & - & - \\
\hline \multirow[t]{3}{*}{ Age, years $(n)$} & $35-49$ & 4,094 & 22 & $0.79(0.52,1.22)$ & 0.29 & $0.96(0.63,1.49)$ & 0.87 \\
\hline & 50-79 (ref) & 67,979 & 468 & 1 & - & 1 & - \\
\hline & $80-89$ & 19,936 & 77 & $0.57(0.45,0.72)$ & $<0.01$ & $0.54(0.42,0.69)$ & $<0.01$ \\
\hline \multirow[t]{3}{*}{ Smoking $(n)$} & Non & 56,018 & 434 & $2.00(1.62,2.48)$ & $<0.01$ & $1.97(1.59,2.44)$ & $<0.01$ \\
\hline & Current (ref) & 27,225 & 111 & 1 & - & 1 & - \\
\hline & Unknown & 8,766 & 22 & $0.70(0.44,1.11)$ & 0.13 & $0.69(0.44,1.10)$ & 0.12 \\
\hline \multirow[t]{2}{*}{ Townsend quintile ( $n$ ) } & 1 (Most affluent) (ref) & 14,322 & 102 & 1 & & 1 & \\
\hline & Unknown & 4,933 & 39 & $1.15(0.79,1.67)$ & $0.19 *$ & $1.23(0.85,1.79)$ & $0.67^{*}$ \\
\hline
\end{tabular}

days. The most commonly prescribed antibiotics were oxytetracycline, doxycycline, and penicillin. The low proportion of COPD patients receiving long-term antibiotics could be explained by the fact that management guidelines for COPD do not recommend this therapy. The choice of older antibiotics could be cost-driven, based on clinical experience, or to reserve newer types of antibiotics for other circumstances. It may be that the latest clinical trial data have yet to be fully translated into clinical practice, as we observed that the use of azithromycin and clarithromycin for long-term therapy increased significantly in the last five years.

There are a number of reasons why macrolides have proved successful in reducing exacerbation frequency. Approximately $50 \%$ of patients with COPD have lower airways that are colonised with bacteria, ${ }^{32}$ and colonised patients have a higher exacerbation frequency. ${ }^{33}$ COPD patients with frequent exacerbations also have higher inflammatory markers, ${ }^{34}$ and macrolides appear to have an anti-inflammatory effect decreasing neutrophil activity and downregulating cytokine expression in various cell types. ${ }^{35}$

\section{Interpretation of findings in relation to previously published work}

To our knowledge, no other study has examined the current prevalence of long-term antibiotic use in COPD patients in a primary care setting. There are a number of clinical trials of long-term antibiotics which suggest they may be of benefit, ${ }^{11-13}$ but current management guidelines do not recommend their use in COPD.

\section{Strengths and limitations of this study}

The main strength of this study is the large primary care population $(6 \%$ of the UK population) so the results are therefore highly generalisable. Other positive features are the use of validated codes for identifying COPD patients ${ }^{25}$ and a long observation period which permitted investigation of this relatively uncommon prescribing practice.

There are some limitations to this study. We identified 63 courses during which there was mention of a condition which might require long-term antibiotics. The most frequent (11/63) was bronchiectasis, which is a condition that can occur independently of COPD but can also be seen on high-resolution computed tomography scans in a high proportion of COPD patients. ${ }^{36}$ Prophylactic antibiotics are sometimes prescribed to patients with bronchiectasis, ${ }^{37}$ but it was not possible to determine whether or not bronchiectasis or the other conditions were the primary cause of the long-term antibiotic prescription; however, exclusion of these 63 courses would produce only a small reduction in the estimated percentage of patients receiving long-term antibiotics from $0.61 \%$ to $0.58 \%$. We could not identify intermittent antibiotic therapy, such as the PULSE study's regime of five days moxifloxacin every four weeks, ${ }^{11}$ as this could not be differentiated from antibiotic therapy for repeated exacerbations.

Pharmacoepidemiology databases are the only feasible way to investigate little-used treatment regimes in a specific disease, but one drawback is that the physician's intention for starting a particular treatment may not always be clear. This was a particular limitation in this study because there is no specific Read code for COPD exacerbation prophylaxis. We also noticed that, in many instances, no diagnostic codes were recorded. However, this is common practice in UK primary care..$^{21,22}$ This might be explained by the treatment being initiated in secondary care and continued in primary care. We noticed that about $10 \%$ of patients who were on antibiotics took these for at least two years, but we could not determine why a long-term antibiotic course was ended and if any specific follow-up was performed.

We found that patients prescribed a long-term antibiotic course were more likely to have a lower $\mathrm{FEV}_{1}$, to be aged between 50 and 79 years, and to be a non-smoker than patients not prescribed longterm antibiotics. Smoking cessation is one of a number of measures - such as optimising treatment with inhaled medication and/or oral 
mucolytics - which could be undertaken before embarking on longterm antibiotic therapy.

Implications for future research, policy and practice

A greater understanding of the mechanisms by which long-term antibiotics reduce exacerbation frequency and airway inflammation is needed. We found a number of patients who had been prescribed antibiotics for over a year. Physicians should carefully follow up patients to whom they have prescribed long-term antibiotics to ensure that course durations are not excessive. We found it difficult to distinguish between treatment of stable COPD and exacerbations of COPD in the computerised recording of consultations. Clear distinction would be helpful as an accurate exacerbation history is important in determining treatment under some management guidelines.

\section{Conclusions}

This study has shown that a small proportion of COPD patients, typically those with more severe disease who are non-smokers, are prescribed long-term antibiotic courses that last a median of 280 days. To help the development of patient management guidelines, further clinical trials are needed to determine the best antibiotic, dose, and treatment schedule for long-term therapy.

\section{Handling editor Tjard Schermer \\ Statistical review Gopal Netuveli}

Conflicts of interest The authors declare that they have no conflicts of interest in relation to this article.

Contributorship GDJ designed the analysis in collaboration with GCD and IP. GDJ undertook data extraction, analysis and interpretation. All authors contributed to the literature review, drafting of the paper and development of core ideas. IP, IN, $J A W$, and GCD were principal investigators who initiated and supervised the study. GDJ is the guarantor.

Funding This study was funded by the National Institute for Health Research Programme Grant for Applied Research, Reference No RP-PG-0109-10056. The study was designed and analysed independent of any input from the National Institute of Health Research.

\section{References}

1. Murray CJ, Lopez AD. Alternative projections of mortality and disability by cause 1990-2020: Global Burden of Disease Study. Lancet 1997;349(9064):1498-504. http://dx.doi.org/10.1016/S0140-6736(96)07492-2

2. Rabe KF, Wedzicha JA. Controversies in treatment of chronic obstructive pulmonary disease. Lancet 2011;378(9795):1038-47 http://dx.doi.org/10.1016/S0140-6736(11)61295-6

3. National Clinical Guideline Centre. Chronic obstructive pulmonary disease: management of chronic obstructive pulmonary disease in adults in primary and secondary care. 2010. Available at: http://guidance.nice.org.uk/CG101/ Guidance/pdf.

4. British Thoracic Society. Burden of lung disease report, 2nd edn. 2006. Available at: http://www.brit-thoracic.org.uk/Portals/0/Library/BTS\%20Publications/ burdeon_of_lung_disease2007.pdf

5. Soler-Cataluna JJ, Martinez-Garcia MA, Roman Sanchez P, Salcedo E, Navarro M, Ochando R. Severe acute exacerbations and mortality in patients with chronic obstructive pulmonary disease. Thorax 2005;60(11):925-31. http://dx.doi.org/10.1136/thx.2005.040527

6. Seemungal TA, Donaldson GC, Paul EA, Bestall JC, Jeffries DJ, Wedzicha JA. Effect of exacerbation on quality of life in patients with chronic obstructive pulmonary disease. Am J Respir Crit Care Med 1998;157(5 Pt 1):1418-22 http://dx.doi.org/10.1164/ajrccm.157.5.9709032

7. Donaldson GC, Seemungal TA, Bhowmik A, Wedzicha JA. Relationship between exacerbation frequency and lung function decline in chronic obstructive pulmonary disease. Thorax 2002;57(10):847-52. http://dx.doi.org/10.1136/thorax.57.10.847
8. Hurst JR, Vestbo J, Anzueto A, et al. Susceptibility to exacerbation in chronic obstructive pulmonary disease. N Engl J Med 2010;363(12):1128-38. http://dx.doi.org/10.1056/NEJMoa0909883

9. Primary Care Respiratory Society. The management of exacerbations of chronic obstructive pulmonary disease in primary care. 2008. Available at: http://www.pcrsuk.org/opinions/acuteexacerbations_final.pdf.

10. Wedzicha JA, Seemungal TA. COPD exacerbations: defining their cause and prevention. Lancet 2007;370(9589):786-96 http://dx.doi.org/10.1016/S0140-6736(07)61382-8

11. Sethi $\mathrm{S}$, Jones PW, Theron MS, et al. Pulsed moxifloxacin for the prevention of exacerbations of chronic obstructive pulmonary disease: a randomised controlled trial. Respir Res 2010;11:10. http://dx.doi.org/10.1186/1465-9921-11-10

12. Albert RK, Connett J, Bailey WC, et al. Azithromycin for prevention of exacerbations of COPD. N Engl J Med 2011;365(8):689-98. http://dx.doi.org/10.1056/NEJMoa1104623

13. Seemungal TA, Wilkinson TM, Hurst JR, Perera WR, Sapsford RJ, Wedzicha JA. Longterm erythromycin therapy is associated with decreased chronic obstructive pulmonary disease exacerbations. Am J Respir Crit Care Med 2008;178(11):113947. http://dx.doi.org/10.1164/rccm.200801-1450C

14. Global Initiative for Chronic Obstructive Lung Disease (GOLD). Global strategy for the diagnosis, management, and prevention of chronic obstructive pulmonary disease (revised 2011). National Institutes of Health, National Heart, Lung and Blood Institute, 2011.

15. Lis $Y$, Mann RD. The VAMP research multi-purpose database in the U.K. J Clin Epidemiol 1995;48(3):431-43. http://dx.doi.org/10.1016/0895-4356(94)00137-F

16. Lewis JD, Schinnar R, Bilker WB, Wang X, Strom BL. Validation studies of The Health Improvement Network (THIN) database for pharmacoepidemiology research. Pharmacoepidemiol Drug Saf 2007;16(4):393-401. http://dx.doi.org/10.1002/pds.1335

17. Szatkowski L, Lewis S, McNeill A, Huang Y, Coleman T. Can data from primary care medical records be used to monitor national smoking prevalence? J Epidemiol Community Health 2012;66(9):791-5. http://dx.doi.org/10.1136/jech.2010.120154

18. Blak BT. Generalisability of The Health Improvement Network (THIN) database: demographics, chronic disease prevalence and mortality rates. Inform Prim Care 2011;19(4):251.

19. Bourke A, Dattani $H$, Robinson $M$. Feasibility study and methodology to create a quality-evaluated database of primary care data. Inform Prim Care 2004;12(3):1717.

20. Abstracts. Pharmacoepidemiol Drug Saf 2011;20(S1):S1-S364. http://dx.doi.org/10.1002/pds.2206

21. Petersen I, Gilbert R, Evans S, Ridolfi A, Nazareth I. Oral antibiotic prescribing during pregnancy in primary care: UK population-based study. J Antimicrob Chemother 2010;65(10):2238-46. http://dx.doi.org/10.1093/jac/dkq307

22. Infectious Disease Research Network. Available at: http://idrn.org/ antimicrobial_prescribing/sdsddrug.htm, 2007.

23. Chisholm J. The Read clinical classification. BMJ 1990;300(6732):1092. http://dx.doi.org/10.1136/bmj.300.6732.1092

24. Townsend P. Health and deprivation: inequality and the North. 1988. Published in the UK by Croom Helm in association with Metheun, Inc.

25. Smith CJ, Gribbin J, Challen KB, Hubbard RB. The impact of the 2004 NICE guideline and 2003 General Medical Services contract on COPD in primary care in the UK. QJM 2008;101(2):145-53. http://dx.doi.org/10.1093/qjmed/hcm155

26. Donaldson GC, Hurst JR, Smith CJ, Hubbard RB, Wedzicha JA. Increased risk of myocardial infarction and stroke following exacerbation of COPD. Chest 2010;137(5):1091-7. http://dx.doi.org/10.1378/chest.09-2029

27. Maguire A, Blak BT, Thompson M. The importance of defining periods of complete mortality reporting for research using automated data from primary care. Pharmacoepidemiol Drug Saf 2009;18(1):76-83. http://dx.doi.org/10.1002/pds.1688

28. Suzuki T, Yanai M, Yamaya M, et al. Erythromycin and common cold in COPD. Chest 2001;120(3):730-3. http://dx.doi.org/10.1378/chest.120.3.730

29. Black P, Staykova T, Chacko E, Ram FS, Poole P. Prophylactic antibiotic therapy for chronic bronchitis. Cochrane Database Syst Rev 2003(1):CD004105.

30. Andridge RR. A review of hot deck imputation for survey non-response. Int Stat Rev 2010;78(1):40. http://dx.doi.org/10.1111/j.1751-5823.2010.00103.x

31. Hurst JR, Donaldson GC, Quint JK, Goldring JJ, Baghai-Ravary R, Wedzicha JA. 
Temporal clustering of exacerbations in chronic obstructive pulmonary disease. Am J Respir Crit Care Med 2009;179(5):369-74. http://dx.doi.org/10.1164/rccm.200807-10670C

32. Wilkinson TM, Patel IS, Wilks M, Donaldson GC, Wedzicha JA. Airway bacterial load and FEV1 decline in patients with chronic obstructive pulmonary disease. Am J Respir Crit Care Med 2003;167(8):1090-5.

http://dx.doi.org/10.1164/rccm.200210-11790C

33. Patel IS, Seemungal TA, Wilks M, Lloyd-Owen SJ, Donaldson GC, Wedzicha JA. Relationship between bacterial colonisation and the frequency, character, and severity of COPD exacerbations. Thorax 2002;57(9):759-64

http://dx.doi.org/10.1136/thorax.57.9.759
34. Bhowmik A, Seemungal TA, Sapsford RJ, Wedzicha JA. Relation of sputum inflammatory markers to symptoms and lung function changes in COPD exacerbations. Thorax 2000;55(2):114-20.

http://dx.doi.org/10.1136/thorax.55.2.114

35. Martinez FJ, Curtis JL, Albert R. Role of macrolide therapy in chronic obstructive pulmonary disease. Int J COPD 2008;3(3):331-50.

36. Davies G, Wilson R. Prophylactic antibiotic treatment of bronchiectasis with azithromycin. Thorax 2004;59:540-1.

37. Patel IS, Vlahos I, Wilkinson TM, et al. Bronchiectasis, exacerbation indices, and inflammation in chronic obstructive pulmonary disease. Am J Respir Crit Care Med 2004;170(4):400-07. http://dx.doi.org/10.1164/rccm.200305-6480C

Available online at http://www.thepcrj.org 


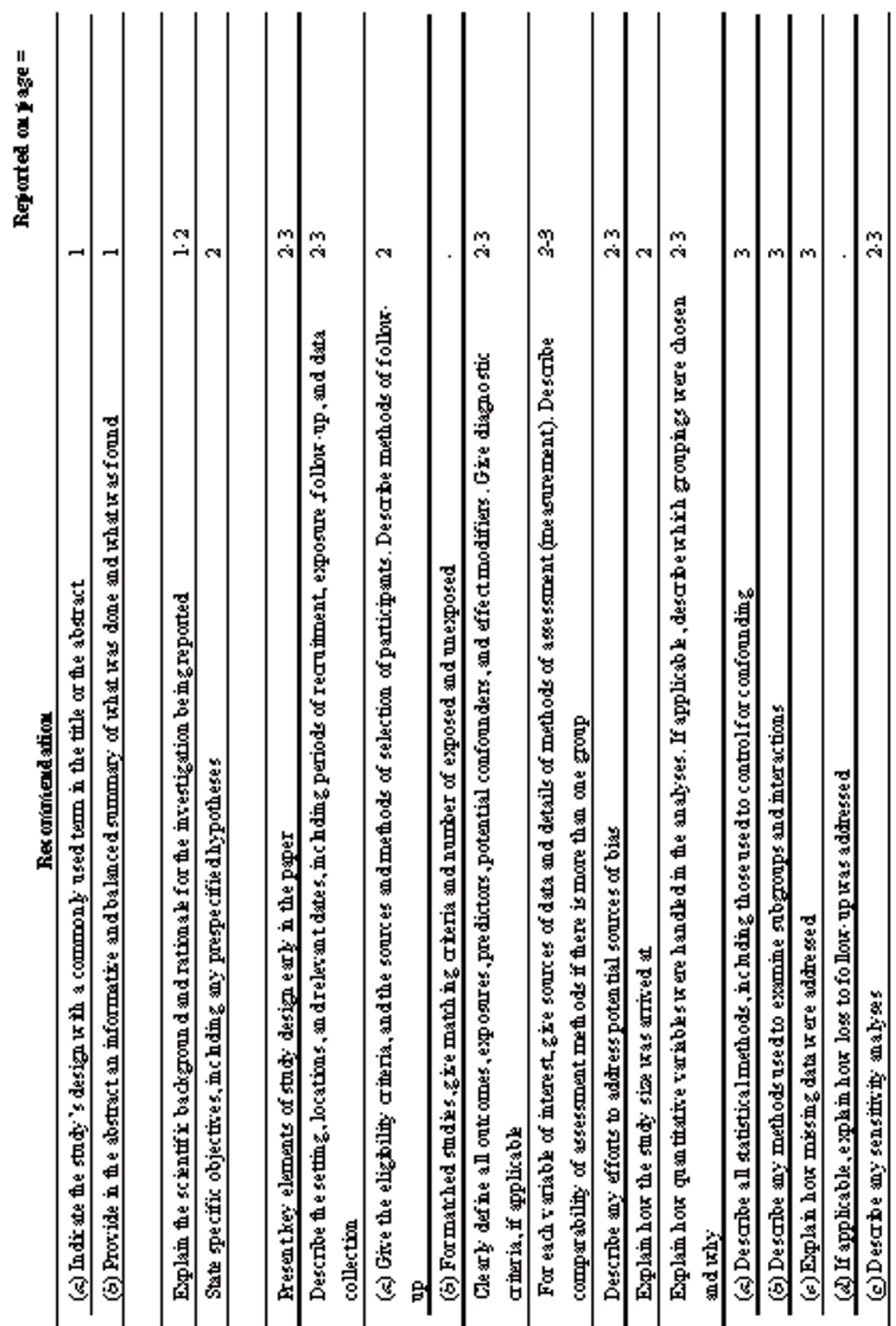

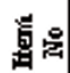

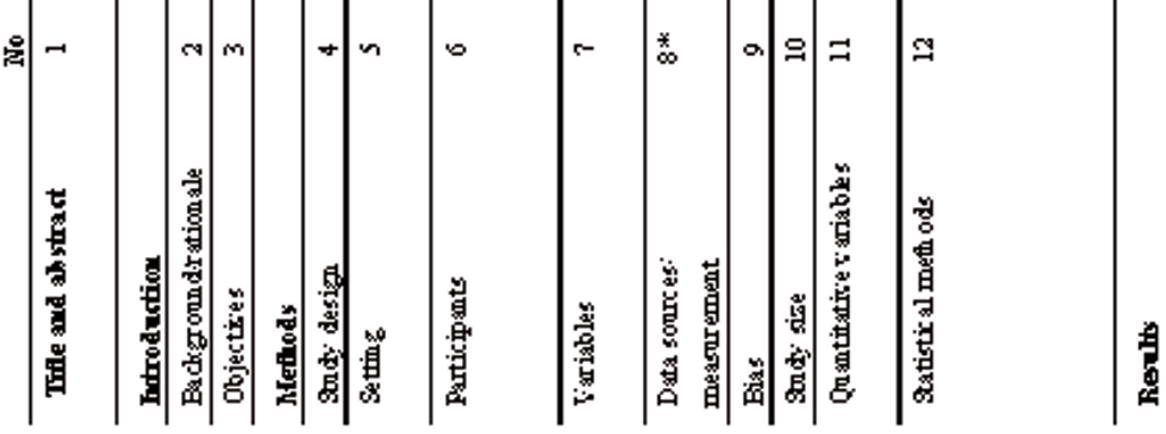




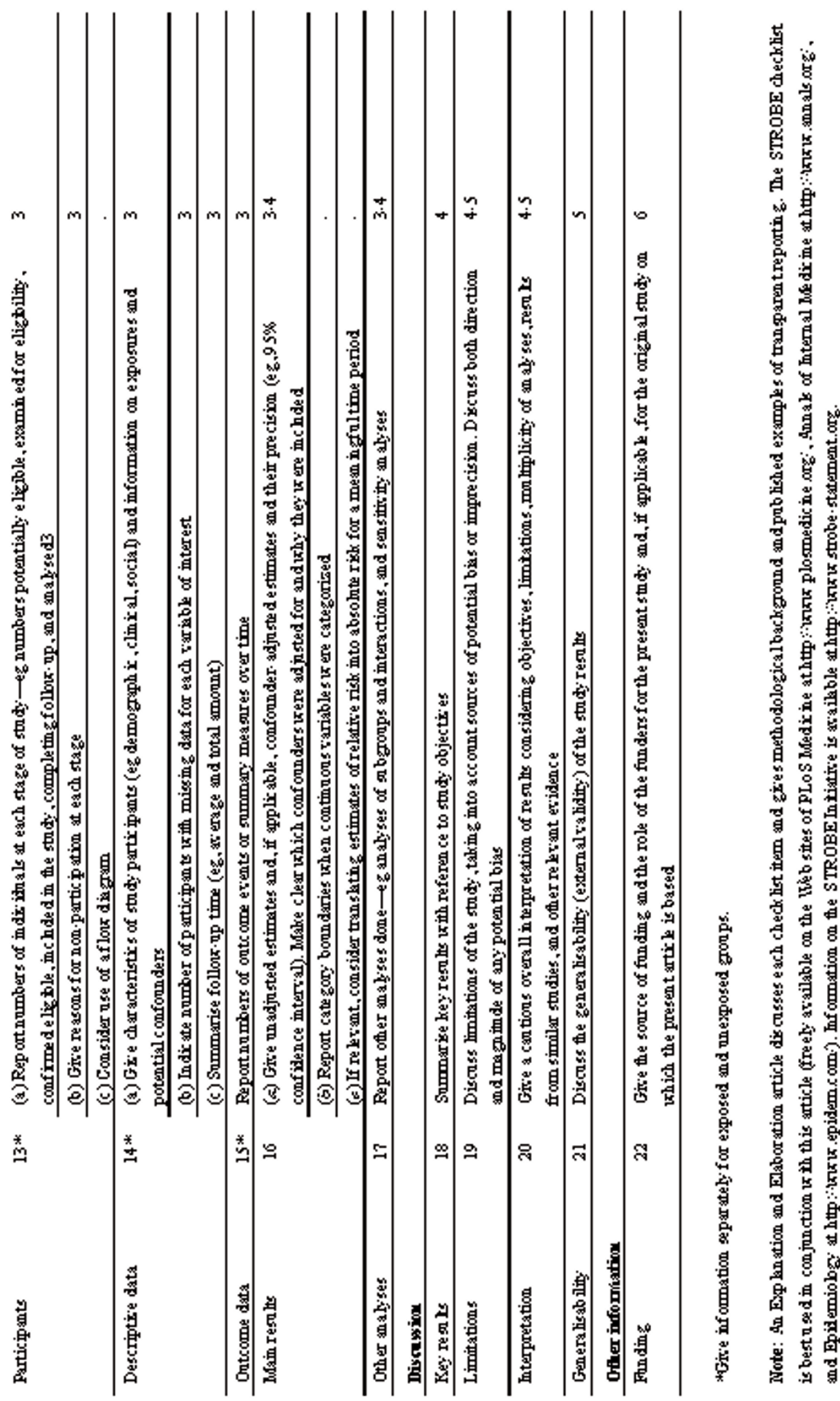

